\title{
A Hierarchical Model to Quantify Burnout Stage of Hotel Industry Employees in Ethiopia
}

\author{
Henok Tibebu ${ }^{1}$, Haileleol Tibebu ${ }^{2 *}$, Bethlehem Solomon ${ }^{3}$ and Tekalegne Diro ${ }^{1}$ \\ ${ }^{1}$ Rift vally University, Ethiopia \\ ${ }^{2}$ Institute of Digital Technologies, Loughborough University London, United Kingdom \\ ${ }^{3}$ School of Public Health, Imperial College London, Medical School Building, St Mary's Hospital, United Kingdom
}

*Corresponding author: Haileleol Tibebu, Institute of Digital Technologies, Loughborough University London, 3 Lesney Avenue, E20 3BS, London, United Kingdom

\section{ARTICLE INFO}

Received: 櫘 September 28, 2021

Published: 嚖 October 04, 2021

Citation: Henok Tibebu, Haileleol Tibebu, Bethlehem Solomon, Tekalegne Diro. A Hierarchical Model to Quantify Burnout Stage of Hotel Industry Employees in Ethiopia. Biomed J Sci \& Tech Res 39(2)-2021. BJSTR. MS.ID.006267.

\section{ABSTRACT}

Evidence suggested that burnout has a detrimental effect on employees and organizations. Hence, burnout prevention is one of the most critical parts of most organizations. Burnout has attracted the attention of many researchers in the past decades. These researchers mainly focus on identifying burnout syndrome, mitigation of burnout, and different methods to predict burnout. In this study, we propose a hierarchical approach to determine the level of burnout stages in hotel industry employees using data from a five-star hotel located in Addis Ababa, the capital city of Ethiopia. To the best of our knowledge, this is the first study that investigates the level of burnout stages of hotel employees in Ethiopia. The proposed model can also be used for non-hotel industries. Our result shows that $51 \%$ of the employees are in the honeymoon stage while $4 \%$ are in onset. Employees who are in chronic and burnout stage are $21 \%$ and $22 \%$, respectively.

Keywords: Burnout; On job-stress; Mental-health; Burnout prevention; Hotel employee burnout

\section{Introduction}

There is high competition in the tourism sector due to the growing numbers of firms like hotels, restaurants, resorts, and tourism-related companies worldwide. Many hotel industries pursue service quality as the core policy to survive in the increasingly competitive marketplace. Hotels often tend to make it mandatory for employees to deliver excellent and extra services to guests to fulfil guest expectations increasingly. This trend is a common and significant cause of employees' work-related psychological Stress and burnout experience, resulting in a high turnover rate. Employee turnover is undoubtedly the main fear for hotel companies. The high turnover rate brings a massive increase in costs, inducing expenses related to employee recruiting and training [1]. Burnout is a condition of emotional exhaustion, reification, and reduced personal accomplishment among individuals who work with people in some capacity. Burnout has been compared with boredom, pressure, displeasure, Unhappiness, estrangement, little confidence, nervousness, tension, conflict, fatigue, poor mental health, crisis, helplessness, vital exhaustion, and hopelessness. Nowadays, burnout is a stable academic issue happening which several investigate consume remained completed then around which several assemblies and seminars are said [2,3].

In this research, we propose a new methodology to quantify different burnout stages of hotel employees. Our approach follows a hierarchical investigation to decide the location of burnout for each employee. We collect data from a five-star hotel located in Addis Ababa, the capital city of Ethiopia, and use this data for experiments and investigation of the method. 


\section{Related Work}

Burnout has attracted the attention of many researchers in the past decades [4-12]. The hotel and tourism industry has a higher impact on the world's economy, which boosts the economy of the tourist recipient countries [13]. Hospitality, a by-product of tourism, is the relationship between the service itself, the service provider, and the service receiver (the guest) in providing a range of services that includes the satisfaction of physical and psychological needs [14]. Hotel employees are constantly under pressure as they need to meet their customers' physical and psychological needs. If these pressures are not handled properly, they will lead the employee to frustration, stress, and loss of interest in their job. Burnout is a condition conceptualized as a result of workplace stress which has not been adequately managed[15,16]. Even if burnout is not yet categorized as a medical condition, it may lead to emotional and physical illness [17]. Burnout happens when an employee is overwhelmed, drained, or unable to meet the continuous demand of their working position. Burnout can affect anyone working in any industry.

The Winona state university adopted Venniga and Spradely's model of stages of burnout to assess the intensity of burnout risk in employees [18]. This model divides the burnout stages into Four.

\section{Honeymoon Phase}

This stage is the beginning of the feeling of burnout, which is not assimilated as burnout in most cases; however, most of the time, it's hard to be diagnosed. Transferring to a new task and assignment of new responsibility is considered a triggering issue. Personal life-related matters like divorce and having a new baby can also often be triggers [19]. This change of situation has an impact on the level of employee job satisfaction. A change of work environment plays a significant role in preventing entering the next stage of burnout. Employees will experience intense optimism, job satisfaction, commitment to tasks, a desire to prove themselves, and a substantial creativity boost [20]. If employers can maintain these positive changes, they may keep their employees in the honeymoon stage for a long time.

\section{Onset Stress}

When a workplace continues, positive incentives are ineffective, employees start to feel that some days are better than others at this stage [21]. Employees sometimes feel like they can't handle the stress at work. Common stress symptoms which may affect employee emotion will be more common. Employees in this stage may experience fatigue, difficulty to focus, irritability, racing heart, sleeping disturbance, headache, anxiety and less self-care [22].

\section{Chronic Stress}

When burnout reaches regular stages, the feeling in the onset stages become more frequent. A decrease in motivation will be noticed more often. At this stage, other people will also see changes in the behaviours like missing deadlines and giving a repetitive excuse. The physical and emotional symptoms intensify at this stage $[23,24]$. Employees in chronic stress may experience anger or aggressive behaviours, missing work deadlines, procrastination, physical pain or illness, instant panic, lack of interest, chronic fatigue and exhaustion, pressure, and social withdrawal from friends or families [20].

\section{Burnout}

When chronic symptoms are not handled properly, they will then transfer to the burnout stage. At this stage, it will not be feasible for the employee to continue working in their position. The continued feeling of powerlessness and failure will eventually run to the belief of disillusionment and despairs [25]. Employees feel like there is no way out of such circumstances and become stranded towards their job. Symptoms at this stage happen more frequently; employees may not even have a single day without feeling. Significant symptoms include Feeling emptiness, self-doubt, denial, desire to move away from work, chronic headache, behavioural changes, pessimistic mood and missing pieces [26].

\section{Methodology}

Initially, a correlation analysis is conducted on the variable to assess their interrelation between each other. All the variables are classified into four groups based on their attributes, honeymoon indicator, onset indicator, chronic indicator and burnout indicator. The category of each variable is decided based on previous research papers. Once all the questionnaires are sub-grouped, each respondent's quantitative responses for questions in the same subgroup are combined and then divided to the total grade assigned to each question which gives us the subgroup average. We then summed up the individual respondents in the subgroup and compared the results against the initially calculated average. If the result is greater than the average in that specific subgroup, then that particular employee has observed all the indications of symptoms in this subgroup. If the result is less than half of the average, that individual is considered free from those symptoms.

After completing the same calculation in all subgroups, the result gives the likelihood of each respondent states whether they are affected by each group or not. However, some employees can be categorized into multiple subgroups of burnout stages. Therefore, a filter is added to decide the current state of each employee. The filter will take all the subgrouped results and only gives back the last positive observation of the burnout stage. For example, suppose an employee is found symptomatic in the onset, chronic and honeymoon stage. In that case, the filter will take the last observation of the positive symptom, which is the chronic stageassuming that the honeymoon and onset stages have already been passed. The flow chart of this methodology is presented in Figure 1 below. 


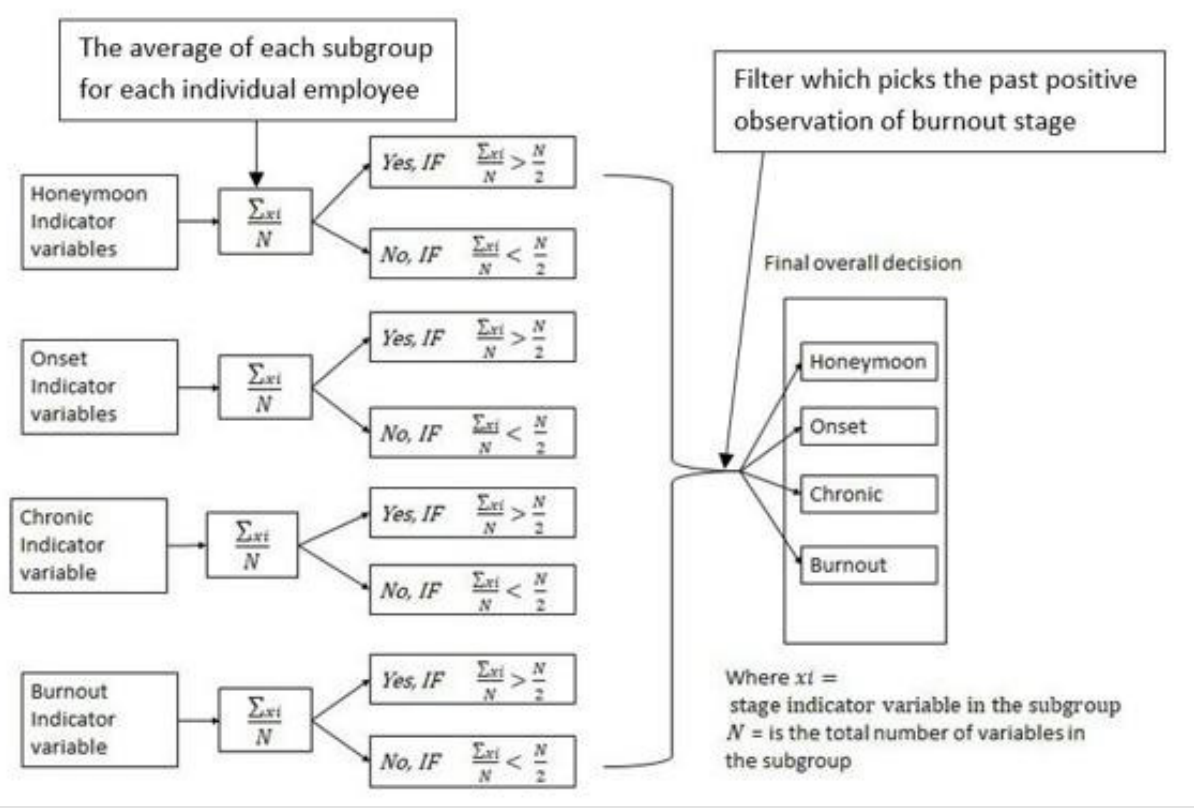

Figure 1: Layout of the methodology.

\section{Results and Discussion}

Initially, descriptive statistics of the data is reviewed, followed by a detailed presentation of results. The results of the data analysis are conducted in the manner described in the methods section of this paper.

\section{Descriptive Statistics of the Data}

Out of the 80 questionaries distributed, 73 (91\%) questionaries were passed the requirement of data quality measures. The remaining 7 (9\%) were either below the data quality requirement of this project or the respondent didn't give back the questionaries. Hence, the analysis is conducted using this data as $91 \%$ of the total sample data is valid and statistically significant to conclude the total population.

Figure 3. present the sample respondent's gender. Out of the total sample, 54(73\%) respondents were female, and 20(27\%) were male. As seen on the chart (Figure 2), female participants are more than males in the sample, which gives the impression that the data is skewed towards the female samples. However, the distribution of gender of the total population of the hotel is also similarly skewed to female. Most hotel industry employees in Ethiopia are female, as the industry recruits female employees more than males. This is especially true in the housekeeping and spa departments with the highest number of hotel employees.

Amongst the hotel respondent, 60 (82\%) of them have a daily base face to face contact with customers, while the $13(18 \%)$ of them have very little or no face-to-face interaction with customers. Departments like housekeeping, spa, front office, security, food and beverage are among the departments with consistent contact with customers. On the other hand, departments like maintenance, finance, and kitchen have very little or no face-to-face contact daily (Figure 3). The relation between face-to-face interaction with customers and burnout is described in the following subsection.

Figure 4. presents the average percentage of the participant by department. This research found that the majority of respondents are in the Spa department (19 or 26\%)). This result is expected because the total number of employees in the spa department is greater than in other departments. The spa department has three times more shifts and many workloads. The housekeeping department is the 2 nd vast department in the hotel, and the percentage of the participant from the housekeeping department is $17(23 \%)$. Housekeeping also has more shifts, and it requires a physical job. The 3rd department is security, with 11(15\%) of the samples. The security department has two shifts, and night shift guards job requires the employee to be awake at night and sleep during the day. The food and beverage department is the 4th broadest department with a total participant of $8(11 \%)$, and this department includes waitress, waiter, and food \& beverage control. The finance, front office and kitchen have equal5(7\%) participant. The last department is maintenance with a total of the participant of $3(4 \%)$. 


\section{Classification of Respondent by gender}

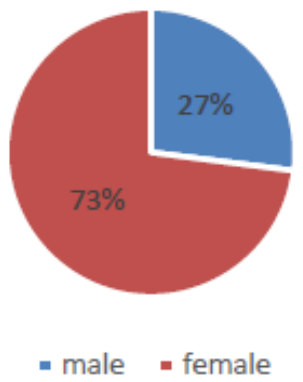

Figure 2: Respondent by gender.

Frequency of participant who have face to face contact with customers

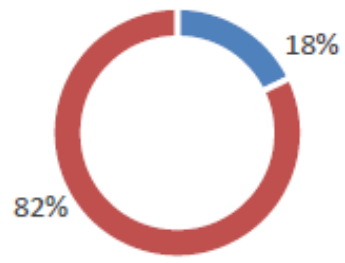

- No customer face to face interaction

- Face to face customer interaction

Figure 3: Frequency of a participant who has a face-to-face contact with the customer.

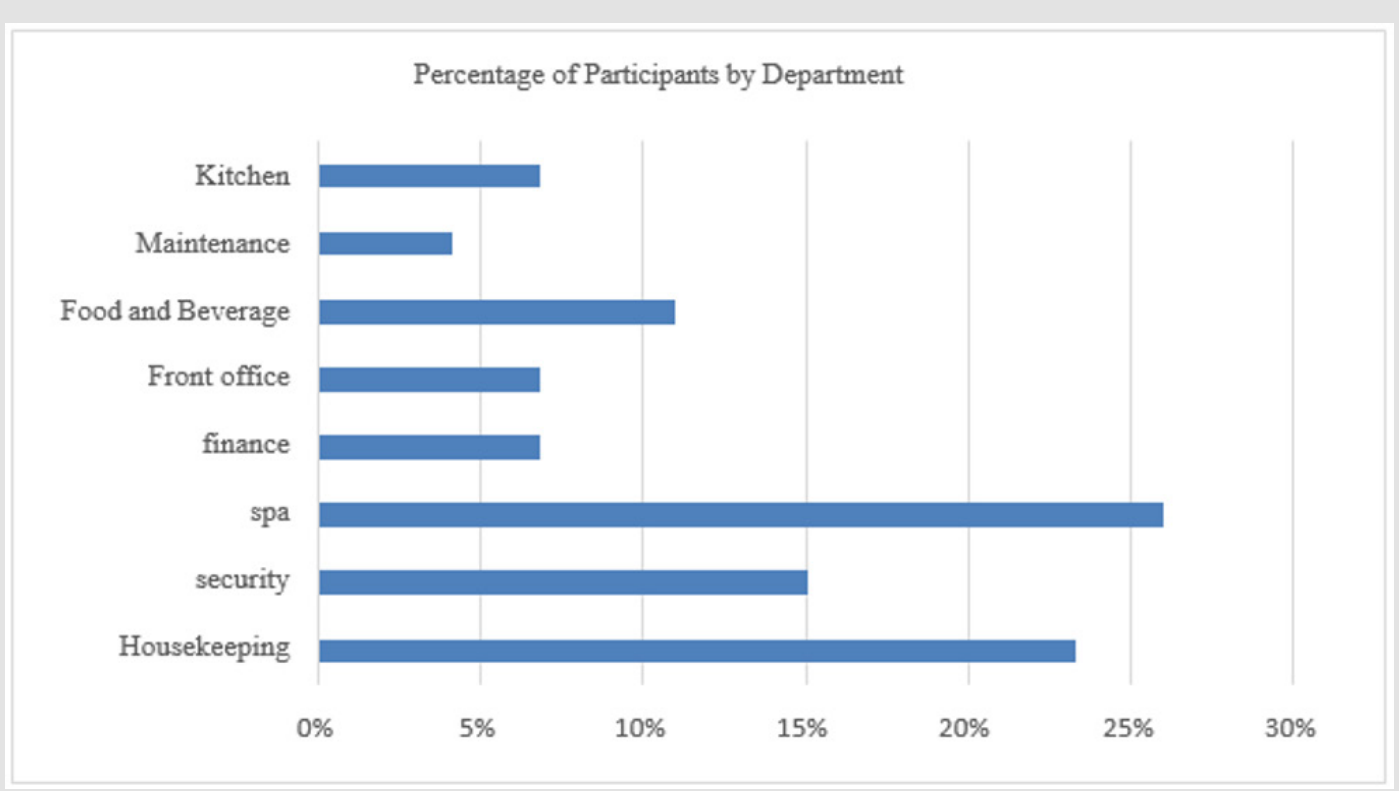

Figure 4: Percentage of the participant by department. 


\section{Correlation of the variables}

The correlation of the variables is calculated, and a heat map of the variables is generated using python package. The purpose of the correlation analysis is to investigate the interrelation of variables in four sub-groups. The aim is to use these interrelations as a signifier of different burnout stages. However, as shown in Figure 5 , most of the variables have no significant positive or negative correlation. More than $95 \%$ of the interrelation are between -3 and 3 , representing a weak correlation among the variables.

As presented in Figure 6, 51.35\% of the employees are on the honeymoon stage, implying that half of the employees are in safest burnout stage. However, the hotel needs to implement a strategy that keeps this group of employees in the same state. Otherwise, there will be a great chance this employee will slip to the onset stage. The total number of employees in the onset stage is significantly less than the other groups $(4.05 \%)$. One of the possible reasons why the number of people in this group is less is that employees might not recognize the symptoms of the onset stage. People on the onset stage might feel like they are in either the honeymoon stage or chronic stage. This depends on the severity of symptoms of the onset stage. It is easy to confuse the indicators of onset with the honeymoon stage and chronic stages. Employees on onset stages are in a better placed to receive treatment for their onset symptoms than the later two stages. Hence, the hotel needs to work on these employees to convert them to the honeymoon stage before the atmosphere converts them to a chronic stage.

Figure 5: Correlation matrix result.

Around $20 \%$ of the hotel employees are in chronic stage, which is a red flag for the hotel to consider. Chronic stage is a stage that must be addressed before employees reached to uncurable phase. The number of employees on this stage cannot be ignored as it can poison the whole work environment. The hotel needs to take intensive measures to tackle this issue by implementing a rigorous treatment plan that needs to be followed by a plan to measure the success of this implementation. The number of employees who are in the final stage (burnout) is $22.97 \%$. This raises an alarm of concern that the hotel was neglecting a significant margin of its employee. As most studies agreed, employees on this stage require an extensive effort to bring them back to other stages. In some cases, it might even be impossible for the employee to be healed at this stage. There are currently $20 \%$ additional employees in the chronic phase, which can shift to burnout stage.

Figure 6. shows, amongst the participant, 51.35\% of them are in the honeymoon stage. Onset stages $4.05 \%$ the smallest amount of the stage. Shifting this population to the honeymoon requires less efforts and resourses than shifting chronic and burnout stage to honeymoon. $20.27 \%$ of the respondents are in chronic stage. This stage has a lower figure comparing to the honeymoon stage. $22.97 \%$ of the participants are in the burnout stage, which is very alarming to the hotel. 


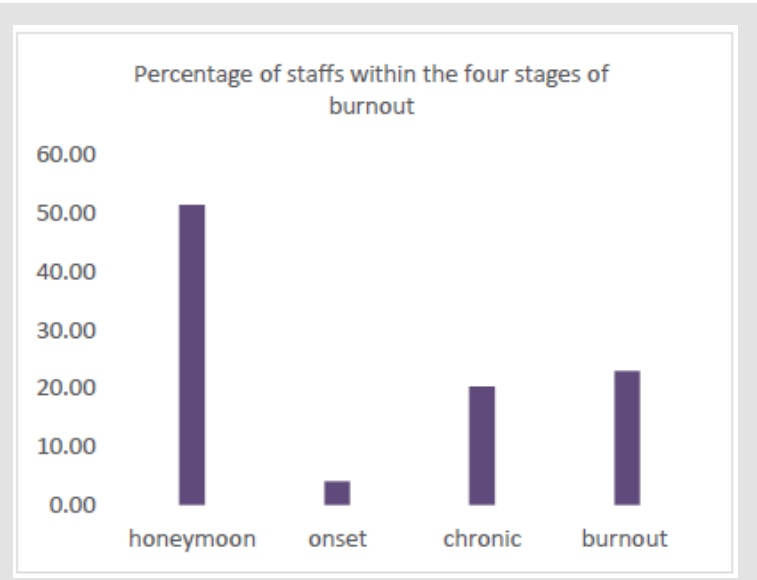

Figure 6: Burnout stages of the five-star hotel employees, which is investigated in this research.

\section{Burnout Stage by Gender}

As explained in the descriptive statistics, most of the employees in this hotel are females. Out of the total sample investigated, $7(9.77 \%)$ male employees are in the honeymoon stage and 32 (44.4\%) female employees are on the honeymoon stage. The honeymoon stage is the desired target stage that all employees and employers want to be. It creates a favourable environment for employees and increases productivity and profit for the company. The result reflects that the percentage of workers on honeymoon stages by gender is less than $50 \%$ for both genders. Therefore, even if $51.3 \%$ of the total employees are on the honeymoon stage, the result by gender shows that the hotel needs to work on both genders. This result revealed a need for a burnout prevention strategy. The number of male employees in the honeymoon stages has a lower percentage than that of female employees. Only $1(1.3 \%)$ of the male and $2(2.78 \%)$ of the female employees are on onset stages, respectively.
Considering the distribution of the participant's gender, the distribution of gender in chronic stage is almost even. The number of male employees in the chronic phase is 4 (5.56\%), while the female employees count 11 (15.28\%). The hotel needs to invest in both genders at this stage as this will be the last chance before it is too late to recover employees from burnout. The number of male and female employees in burnout stage is the same, $9(12.5 \%)$. However, as described in Figure 3, the number of samples taken from male and female employees is not equal. Female respondents count $73 \%$, and male respondents estimate $27 \%$. Hence, the number of male employees in burnout stage is $21 \%$ higher than that of female employees. The hotel needs to investigate why male employees in burnout stage are higher than the female. The hotel needs strict treatment measures to decrease these employee numbers, especially male employees in the last stage. As some studies suggested, it is severely challenging to treat employees who are on the final stage; it's more often uncurable at this stage (Figure 7).

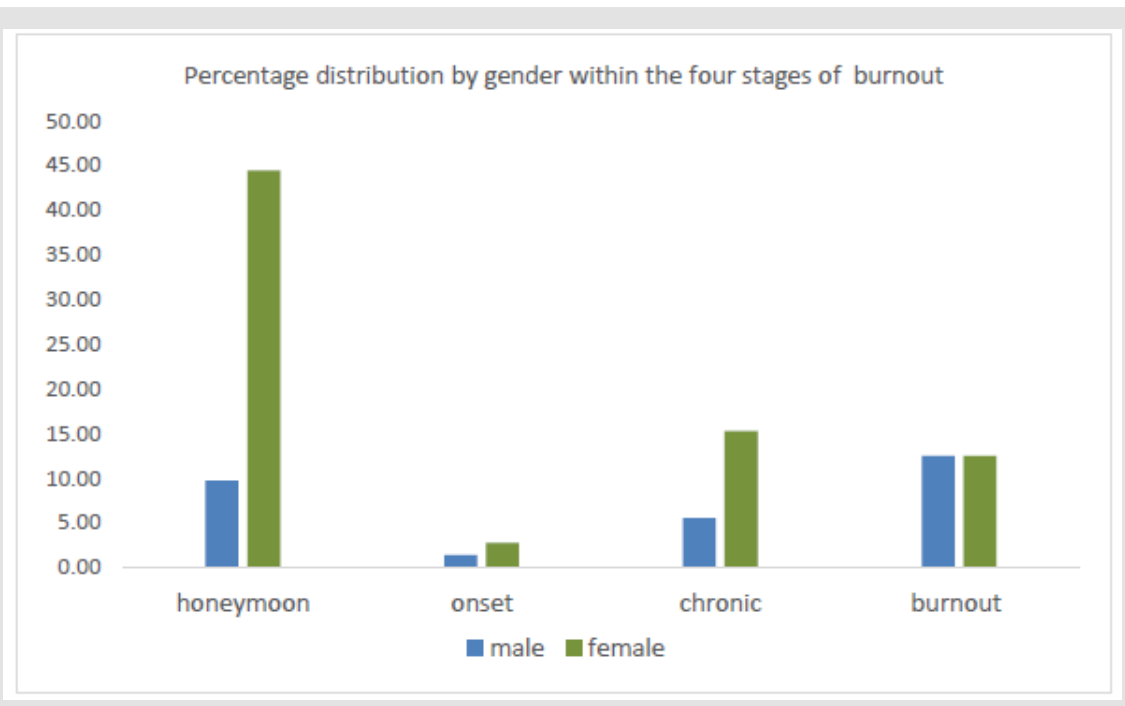

Figure 7: Burnout difference by gender. 


\section{Burnout Stages by Face-To-Face Contact with Customers}

The result presented in Figure 8 showed the distribution of burnout stages related to employees' job responsibility of faceto-face interaction with customers. The departments with faceto-face contact with customers are a spa, housekeeping, security front office, and the maintenance team. On the other hand, the Main kitchen. Finance and part of the maintenance team don't have face- to-face contact with customers. The result shows that employees who have a face-to-face interaction with customers have a higher margin in the four burnout stages. Hence, this indicates the possible link between face-to-face contact with customers and burnout. One of the probable causes for this is that this employee takes the load handling customers' demands, complaints and enquires. Therefore, the hotel needs special training for this group of customers, which can decrease the pressure of their position.

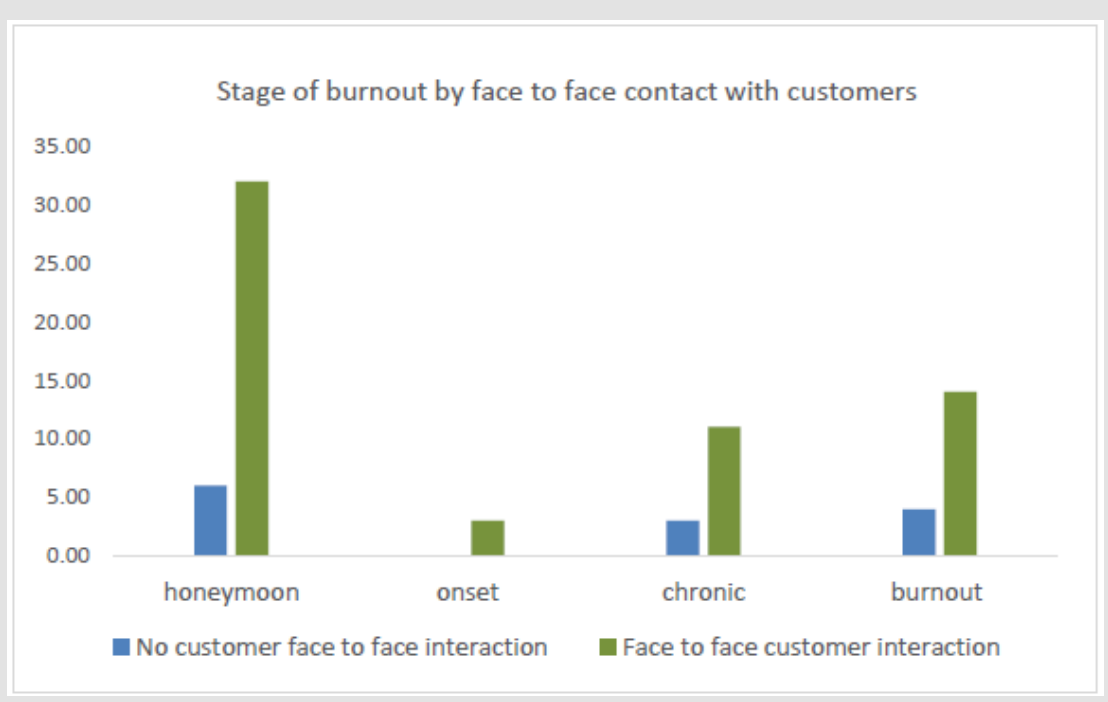

Figure 8: Stages difference by face-to-face contact.

\section{Burnout Stages Distribution by Department}

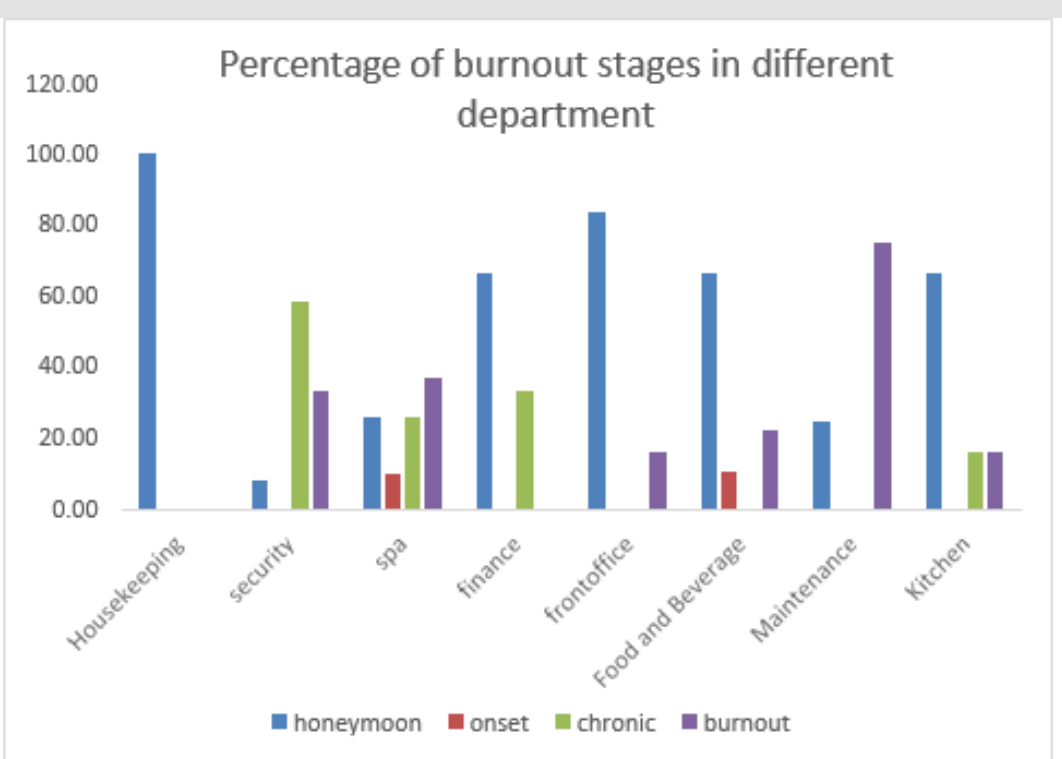

Figure 9: Stages of burnout in department.

The housekeeping department is the only department where $100 \%$ of employees are on the honeymoon stage, followed by the front office (80\%) and food and beverage (64\%). There are few employees in onset stage from the food and drink and spa departments. The majority of the chronic stage employees are from the security department, followed by spa and finance. Housekeeping 
is the department that the hotel needs to critically work to save its employee from moving in the burnout stage. The result also shows that majority of the employees in maintenance departments are in the burnout stage. Security, spa food and beverage, front office and kitchen has a share of employees in burnout stages. Based on these results, the hotel must design the best possible combination of treatment for each department as per its need.

\section{Conclusion}

In this research, we propose a new hierarchical methodology to evaluate the burnout stage of employees in hotel industry. Using the proposed method, we quantify the burnout stage of five start hotel employees. The hotel investigated in this study is located in Addis Ababa, the capital city of Ethiopia. Our result shows that $51 \%$ of the hotel employees are in the honeymoon stage while $4 \%$ are in onset. Employees who are in chronic and burnout stage are $21 \%$ and $22 \%$, respectively. We quantify results by gender, department, and face-to-face contact with the customer. The proposed method can also be used to quantify employee burnout stages in other sectors, different from hotel industries.

\section{Competing Interests}

The authors declare that they have no competing interests.

\section{References}

1. H Han, Quan Wei,Amr Al-Ansi,Hyunah Chung (2020) A theoretical framework development for hotel employee turnover: Linking trust in supports, emotional exhaustion, depersonalization, and reduced personal accomplishment at workplace, Sustain

2. (2020) Burnout in Health Care Providers. J Organ Psychol.

3. C Maslach, MP Leiter (2017) New insights into burnout and health care: Strategies for improving civility and alleviating burnout. Med Teach.

4. Yuxia Zhang, Chunling Wang, Wenyan Pan, Jili Zheng, Jian Gao, et al. (2020) "Stress, Burnout, and Coping Strategies of Frontline Nurses During the COVID-19 Epidemic in Wuhan and Shanghai, China. Front Psychiatry.

5. Huaruo Chen, Fan Liu, Liman Pang, Fei Liu, Tingting Fang, et al. (2020) Are you tired of working amid the pandemic? The role of professional identity and job satisfaction against job burnout. Int J Environ Res Public Health.

6. R Žutautienė, R Radišauskas, G Kaliniene, R Ustinaviciene (2020) The prevalence of burnout and its associations with psychosocial work environment among kaunas region (Lithuania) hospitals' physicians. Int J Environ Res Public Health.

7. C Dall'Ora, J Ball, M Reinius, P Griffiths (2020) Burnout in nursing: A theoretical review. Human Resources for Health.
8. C Maslach, MP Leiter (2016) Understanding the burnout experience: Recent research and its implications for psychiatry. World Psychiatry.

9. A Algunmeeyn, F El-Dahiyat, MM Altakhineh, M Azab, ZUD Babar (2020) Understanding the factors influencing healthcare providers' burnout during the outbreak of COVID-19 in Jordanian hospitals. J Pharm Policy Pract.

10. Michelle P Salyers, Kelsey A Bonfils, Lauren Luther, Ruth L Firmin, Dominique A White, et al. (2017) The Relationship Between Professional Burnout and Quality and Safety in Healthcare: A Meta-Analysis. J Gen Intern. Med.

11. ARC Sousa, JI de B Mourão (2018) Burnout in anesthesiology. Brazilian Journal of Anesthesiology.

12. NB Pokhrel, R Khadayat,P Tulachan (2020) Depression, anxiety, and burnout among medical students and residents of a medical school in Nepal: A cross-sectional study. BMC.

13. M Dawson, JA Abbott, S Shoemaker (2011) The Hospitality Culture Scale: A measure organizational culture and personal attributes. Int J Hosp Manag.

14. MR Davahli, W Karwowski, S Sonmez, Y Apostolopoulos (2020) The hospitality industry in the face of the COVID-19 pandemic: Current topics and research methods. International Journal of Environmental Research and Public Health.

15. RC Gorter, G Albrecht, J Hoogstraten, MAJ Eijkman (1998) Work place characteristics, work stress and burnout among Dutch dentists. Eur J Oral Sci.

16. C Maslach, WB Schaufeli, MP Leiter (2001) Job burnout. Annu Rev Psychol.

17. P Koutsimani, A Montgomery, K Georganta (2019) The relationship between burnout, depression, and anxiety: A systematic review and meta-analysis. Frontiers in Psychology.

18. (1990) WS University's, "Stages of Burnout," B, Chapter 9, 1990, [Online].

19. N Sumi, Y Yoshida, N Sugimura, R Yano (2018) Investigation of the Burnout Stages Experienced by Nurses Working in Hospitals and Related Factors. Open J Nurs.

20. (2020) Sanctuary, "5 stages of burnout: how to notice the symptoms.

21. JI Živojinović, D Backović, G Belojević, O Valčić, I Soldatović, et al. (2020) Predictors of burnout among Belgrade veterinary students: A crosssectional study. PLoS One.

22. Simona Zacharavo (2020) "Phase of Burnout.

23. T Chandola, E Brunner, M Marmot (2006) Chronic stress at work and the metabolic syndrome: Prospective study. Br Med J.

24. C Kersting, L Zimmer, A Thielmann, B Weltermann (2019) Chronic stress, work-related daily challenges and medicolegal investigations: A crosssectional study among German general practitioners. BMC Fam Pract.

25.S Bellingrath, T Weigl, BM Kudielka (2009) Chronic work stress and exhaustion is associated with higher allostastic load in female school teachers. Stress.

26. (2008) BS Care, The Signs and Dangers of Job Burnout. 


\section{ISSN: 2574-1241}

DOI: $10.26717 /$ BJSTR.2021.39.006267

Haileleol Tibebu. Biomed J Sci \& Tech Res

(c) (P) This work is licensed under Creative (c) Commons Attribution 4.0 License

Submission Link: https://biomedres.us/submit-manuscript.php

\begin{tabular}{ll} 
BIOMEDICAL & Assets of Publishing with us \\
RESEARCHES & - Global archiving of articles \\
& - Immediate, unrestricted online access \\
\hline ISSN: $2574-1241$ & - Rigorous Peer Review Process \\
\end{tabular}

